\title{
A year of action
}

\author{
This year is make or break for climate and a sustainable future. The opportunity to make genuine \\ progress on these grand societal challenges must not be squandered.
}

Later this year, the twenty-first Conference of the Parties (COP21) to the United

Nations Framework Convention on Climate Change (UNFCCC) is expected to agree an international and legally binding agreement on climate action. Preparation for COP21 is underway, with countries slowly beginning to communicate their planned post-2020 climate actions (intended nationally determined contributions) to the UNFCCC secretariat (http://go.nature.com/OUU2rq). But with only 18 pledges so far on the table there is still a long way to go, and it is by no means clear that the global community is prepared to do what is needed to limit warming to $2{ }^{\circ} \mathrm{C}$, let alone to achieve the more ambitious targets called for by some developing countries.

It is not just climate change that is being addressed on the international policy stage this year; sustainable development will also be in the spotlight, with the United Nations Summit to Adopt the Post-2015 Development Agenda being held in New York in September. The summit is expected to agree and set in motion the sustainable development goals (SDGs) first mooted at the Rio+20 Conference in 2012. These new goals will run to 2030, and follow on from the eight Millennium Development Goals established in 2000, which have achieved varying levels of success (www.who.int/mediacentre/factsheets/ fs290/en). The SDGs will need to account for future climate change, making 2015 a crucial year for international action in both the climate change and development spheres.

These upcoming meetings have spurred action from many sections of society and encouraged debate on what people want for the future. For example, in an encyclical letter to Catholics, Pope Francis acknowledges that anthropogenic climate change is real and that it has potentially serious implications for humanity (http://go.nature.com/7IbiB5). Pope Francis notes the overconsumption by rich nations and the impact this is having on the poor, as well as the lack of global action on climate change, and encourages individuals to make personal changes.

Reaching a potentially different audience - certainly a trendier one - boy band One Direction launched Action/1D (http://action1d.onedirectionmusic.com),

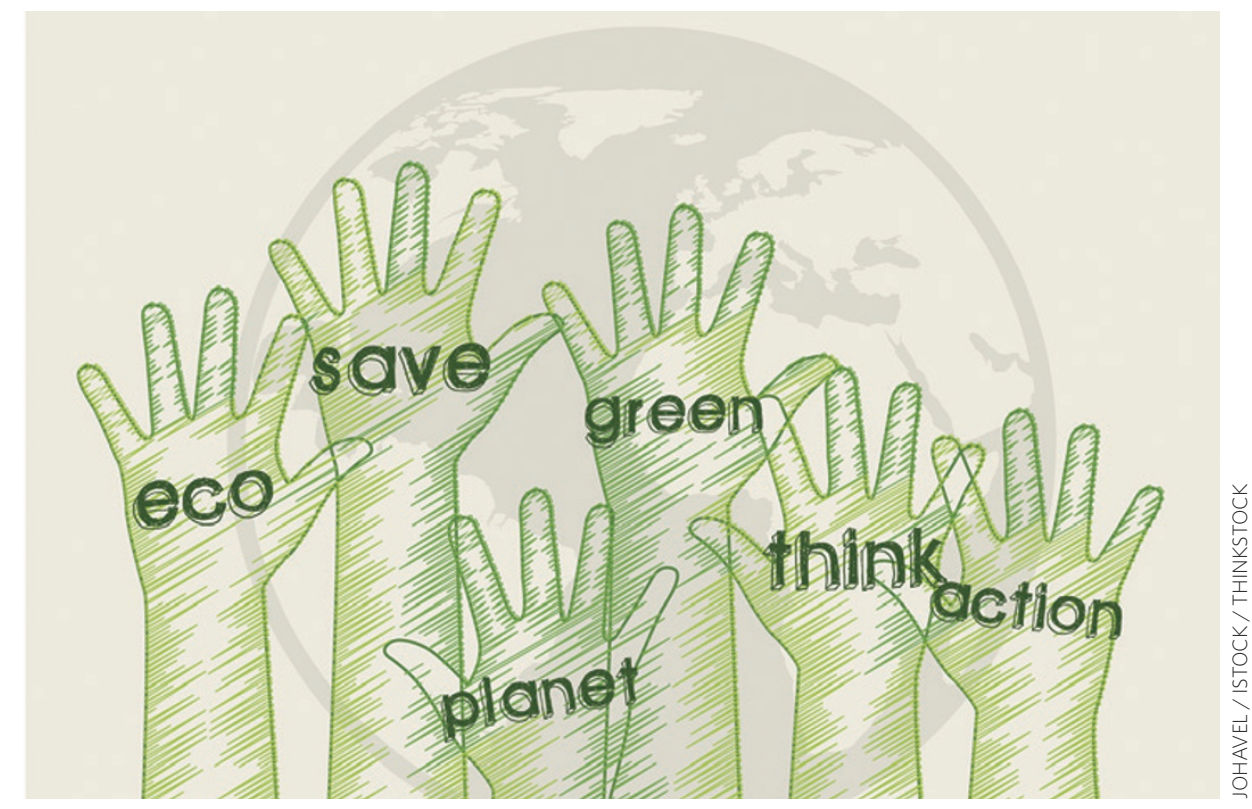

part of action/2015 (http://action2015.org), which strives to inspire individuals to make their voices heard and influence world leaders. Alongside other similar initiatives, these will help open up the debate and engage a wider group of actors than just policymakers and politicians.

Individuals' perceptions of climate change are important in determining the level of public support for global actions to tackle it. But their experiences of local weather can also affect their climate change beliefs. Indeed, personal exposure to extreme events such as heatwaves, droughts, storms and floods can motivate people to take their own action on climate change - by using energy and resources more efficiently or sparingly, for example. Flavio Lehner and Thomas Stocker (page 731) assess the influence of local experiences versus global change on climate change beliefs, showing that the former can be critical. Their analysis reveals a steady increase in the share of the world population exposed to warmer-thannormal temperatures. This is not what would be expected if one were just to consider global mean temperature anomalies, or indeed the much-hyped slowdown in surface temperatures over recent decades, but it is in line with current climate models. Presenting the information in this way, rather than talking about global averages, should help increase confidence in climate model projections.

How best to convey climate change science is an ongoing discussion. The IPCC has prepared five reports since 1990, each including a summary for policymakers, yet there is concern that these reports have not been sufficiently effective in communicating information about climate change, especially to the general public (see, for example, the recent Commentary by Richard Black (Nature Clim. Change 5, 282-284; 2015).

So how can communication improve? Every discipline speaks its own language, with terminology and jargon specific to a field, and this can be impenetrable to outsiders. But greater contact and discussion between fields should lead to a 'common' language. No doubt with this in the minds of its organizers, Our Common Future Under Climate Change (a meeting held in Paris this July) brought together scientists from a diverse range of disciplines, along with stakeholders and the general public to discuss and prepare for COP21 and its outcomes.

If, as so many people hope, 2015 sees the emergence of a grand coalition of nations and citizens determined to act individually and collectively on climate change and sustainable development, it will be a year to remember for all the right reasons. 